\title{
The Research on the Path of Coordinated Development of Energy Tapping and Environmental Protection
}

Zijian Jia*

Henan University, Kaifeng 453007, Henan province, China. E-mail: 419986496@qq.com

Abstract: The rapid development of the society and economy in China has led people's standard of living to a higher level. However, the issues between energy development and environmental protection have become more pressing. In order to fundamentally solve the contradiction between environmental protection and energy development, it is necessary to deepen the awareness of protecting the environment and reasonably tap into the power of energy. Satisfy the two purposes, as in cherishing the environment and supplying energy for social development, at the same time. This paper provides an in-depth analysis of the problems of energy development and seeks a coordinated development path between energy development and environmental protection.

Keywords: Environmental Protection; Energy Development

\section{Introduction}

In today's rapid economic development, China's industry has ushered in an important moment of development. However, while industrialization has brought development, it has also brought disadvantages, such as pollution and damage to the environment. In the present form of development, a large amount of energy is exploited. Despite the advocacy of rational use of energy, there is still serious waste on natural resources, a phenomenon that accelerates the disappearance of some non-renewable energy sources and thus harms sustainable development. In order to reasonably improve the problems of environmental pollution and energy waste, we must reasonably control the development of energy exploitation and strengthen the implementation of environmental protection while scientifically pursuing economic development. Establishing the right awareness of environmental protection has profound significance to the development of the economy.

\section{The current environmental pol- lution issues in China}

Throughout the energy extraction in the country, there are serious environmental problems in the economic development, which are shown as follows:

(1) Industrial production emits pollutants and continuous emission of harmful substances has led to the ecology unable to purify the environmental pollution caused by pollutants through natural purification, failing in many regions to meet the environmental quality standards set by the state.

(2) In today's rapid economic development, chemical waste has also brought new environmental problems. The pollution capacity of chemical waste is larger and the pollution lasts longer than conventional industrial emissions. The problems brought by new pollution have posed threat to the safety of people's lives.

(3) Chemical waste and electronic waste can bring serious pollution to the water resources and soil on which

Copyright (C) 2021 Zijian Jia

doi: 10.18686/pes.v3i1.1389

This is an open-access article distributed under the terms of the Creative Commons Attribution Non-Commercial License

(http://creativecommons.org/licenses/by-nc/4.0/), which permits unrestricted non-commercial use, distribution, and reproduction in any medium,

provided the original work is properly cited. 
human beings live on.

(4) With the increase in population, China's demand for coal resources has been increasing. The increasing amount of coal consumption by the large population will seriously affect the environment.

The urbanization in China and the influx of young people into the cities have made it more difficult to protect the environment. For this reason, China urgently needs to change the way it develops its economy - to change production methods that produce pollutants and consume a lot of energy. At the same time, citizens should be more aware of the seriousness of environmental pollution and strengthen the protection of the environment.

\section{Overview of China's energy situ- ation}

China has very considerable energy possession and rich natural resources, but due to the large population, the source owned by a single person per capita is limited, which has led to uneven distribution and low efficiency. While China is facing severe environmental problems, the author holds the view that this phenomenon is caused by the lack of a perfect system that can effectively control energy use and exploitation, rather than any technical reasons. The imperfect system has led to a lack of rational use of efficient and clean energy technologies $^{[1]}$.

Although the energy reserves in China are comparatively large due to its vast territory, the per capita use is relatively small because of the large population, which results in China's dependence on the increasing imports of energy. When energy becomes replenished with the development of the economy, energy production and sales will become asymmetric and lead to China predictably become more dependent on imports. This phenomenon will seriously affect China's economic development and the construction of national defense security. The gradual reduction of non-renewable energy sources makes the price of energy escalate and out of control. To solve this problem, it is essential to control the extraction of energy so that the goal of sustainable socio-economic development can be achieved ${ }^{[2]}$.

\section{The importance of strengthening}

\section{environmental protection and new energy development}

To meet the needs of people's living and to make energy last, energy resources need to be exploited and utilized appropriately. People need to pay close attention to the balance of the ecosystem and then put environmental protection into practice. People should not constantly request access to natural resources, but rather, people need to live in harmony with nature. We need to learn from the lessons of history and take the essence out of the consequences, which requires people to study the valuable experience of our predecessors to extract energy without destroying the ecosystem. In particular, safety measures of chemical substances are extremely important. Safety protection needs to be strengthened to prevent damage to the environment caused by chemical substances $^{[3]}$. However, it is not enough to be aware of the importance of environmental protection, it is also necessary to strengthen the execution of the environmental protection measures to avoid damages at a practical level. Therefore, it is the responsibility of everyone to protect the environment, starting from and executing energy-saving measures in their daily lives.

\section{The relationship between envi- ronmental protection and develop- ment of new energy}

Energy development and use are important to the task of building environmental protection. It is essential to strengthen the execution of environmental protection to realize the value of natural resources. For the sake of self-interest, there are often people who extract energy and natural resources at the expense of damaging the environment. But once the environment is destroyed, it will inevitably cause a negative impact on social development. This should alarm people to take a long-term view in the process of energy extraction and look at it from a development perspective - if the environment is damaged, people will lose the life savings, not to mention the stagnation of economic growth. In order to maintain the sustainability of economic development, the execution of environmental protection must be strengthened, and energy exploitation must be controlled. This is the basis for sustainable development by achieving good energy recycling through regulations. 


\section{Suggestions for the development of new energy in China}

\subsection{The development of new energy needs considered planning}

The functions of the government have failed to achieve transformation - some government officials focus on development projects while neglecting planning work, resulting in a huge gap between the outcomes and planning, while in fact, the measures of environmental protection are usually not deliberately planned. The lack of constraints leads to a serious waste of resources. Therefore, to do a better job in the task of environmental protection, it is necessary to have a global view, making energy development planning from a long-term perspective to formulate binding regulations. When planning energy development, several aspects should be taken into account: first, the problem of synchronization of power supply and power grid should be given more attention, and reasonable solutions should be found to ensure project benefits; second, deal with the efficiency of the relationship between energy development and energy cleanliness, focusing on the development direction of synchronous and local energy consumption; third, in order to effectively avoid energy waste, the planning process should strictly adhere to the basic principles of localization $^{[4]}$.

\subsection{The development of new energy should comply with the priority principle of energy saving and emission reduction}

If we want to solve the problem between energy development and environmental protection, we must first carry out technological transformation to the industries, whose productions are energy-consuming with high emission of industrial waste. While strictly abiding by the basic principle of prioritizing energy conservation and emission reduction, we should adopt a variety of market development methods to promote energy conservation and emission reduction and avoid a single method of governance. In addition, balancing the relationship between the level of economic development and the environment protection around different regions and clarifying the goals of energy conservation and emission reduction are also good measures that should be carried $\mathrm{on}^{[5]}$.

\subsection{The development of core technology of new energy}

To plan a rational energy development, the development of core technology is crucial. Combined with the current situation, the author has found that the core technology of new energy has not been fully mastered. Many key facilities and devices still cannot be made independently and are highly dependent on imports. Therefore, the relevant departments should strengthen technology innovation and implement supporting processes such as testing and certification of new technology and facilities. Moreover, relevant departments should strictly abide by the market mechanism to bring more funds and allowance into the development of new energy, while providing tax incentives to enterprises with independent and innovative research and development, which is helpful to realize the conversion of scientific research $^{[6]}$.

\subsection{The design of systematic policies for de- velopment of new energy}

In order to improve the capacity of enterprises to independently innovate, the relevant departments should develop a scientific energy pricing policy so that energy subsidies are available to all enterprises, which in turn will enable an effective connection between approved energy projects everywhere.

\section{Conclusion}

Strengthening environmental protection is essential to the development of modern society, so strengthening environmental protection has a very important role in sustainable development. For sustainable development, people should not only have a better awareness of environmental protection but also take action and actively participate in the work of protecting the environment to promote the harmonious development between humans and the environment.

\section{References}

1. Lu Y, Wang F. Explore environmental protection and new energy development from the perspective of high school students (in Chinese). Journal of Green Science and Technology 2019; (02): 115-116, 118.

2. Meng $X$. A brief discussion on measures on energy environmental protection in rural areas (in Chinese). 
Agriculture and Technology 2017; 37(24): 246-247.

3. Tian Q. Promoting win-win between energy development and environmental protection (in Chinese). Xinjiang Renda (in Chinese) 2015; 389(8): 26-27.

4. Yin X, Sun P. Japan's new energy development and utilization policy and its enlightenment. China Management Informationization 2018; 21(9): 102105.
5. Wu F. "Resource curse" and economic development: A typical analysis to Shanxi province. On Economic Problems 2007; (10): 24-27, 66.

6. $\mathrm{Ru} \mathrm{X}$. On the balanced management of agriculture, energy, environmental protection and social development (in Chinese). China Strategic Emerging Industry 2019; (40): 211. 